\title{
Fungi causing rots in onions at storage and market
}

\author{
M.A.M. Ara, M.L. Khatun and M. Ashrafuzzaman \\ Department of Plant Pathology, Bangladesh Agricultural University, Mymensingh-2202, Bangladesh
}

\begin{abstract}
Five varieties of diseased onion samples, four local (Taherpuri, Faridpuri, Kalashnagari, and Zitka) and one Indian (Pusa Red) were collected from different markets of Mymensingh, to isolate and identify the associated fungi. Five different fungal species belonging to three genera were repeatedly isolated. Healthy looking and diseased onions were kept at room temperature. The population of associated fungi increased proportionately with the duration of storage period. The isolated fungi were Aspergillus niger, Aspergillus flavus, Penicillium spp., Fusarium oxysporum and Fusarium moniliforme. Healthy onion bulbs were inoculated (with injury and without injury) with these fungi. Individual fungi produced distinguishable symptom of disease in incubation chamber at $22-23^{\circ} \mathrm{C}$ temperature. After 30 days of inoculation, bulbs showed comparatively low amount of disease development than those at 60 and 90 days. Maximum disease development was found in the variety Pusa Red (with injury) and it was minimum in Zitka variety (without injury).
\end{abstract}

Keywords: Fungi, Onion, Disease development

\section{Introduction}

Onion (Allium cepa L.) is one of the most important and familiar spice (family-Alliaceae) crops throughout the world. They are used everyday in the kitchen and on the dining table creating a demand for its availability in the market. But, in most of the countries onions are harvested once a year needing its storage where it loses weight due to continuous loss of water and dry matter. The most serious loss arises from storage rots due to bulb rotting microorganisms and also from unwanted sprouting (Jones and Mann, 1963). About 15 different fungal species are reported responsible for the onion diseases in the storage and transit all over the world for which the loss may go up to $40 \%$ (Aiyer, 1980). The most destructive diseases in storage are black mould rot (Aspergillus niger), blue mould rot (Penicillium spp.), Fusarium bulb rot (Fusarium spp.), basal rot (Fusarium monilifome), Aspergillus rot (Aspergillus spp.) etc. A. niger and $A$. flavus infect bulbs at high temperature with high relative humidity while Penicillium spp. may destroy bulbs even at low temperature. Infections by Penicillium spp. may produce the mycotoxin Penitrem $A$, which has been recently implicated in tremorgenic toxicosis (Overy et al., 2005) in man and animals. Likewise A. flavus infection may produce aflatoxin which is poisonous to human health. The objective of this experiment is to identify the pathogenic fungal isolates obtained from the naturally infected bulbs and varietal differences in susceptibility of different onion varieties.

\section{Materials and Methods}

\section{Collection of samples}

Onion samples $1 \mathrm{Kg} / 20 \mathrm{Kg}$ bags were collected randomly from retailer shops of different areas of Mymensingh. The samples were pooled together to form one composite sample for a market. The onions were closely inspected and sorted out depending symptoms of infection. 


\section{Isolation}

Isolation of associated fungi with the symptom bearing onions was done by employing usual tissue planting method on both PDA medium and moist chamber maintaining asceptic conditions incubating at room temperature for 3-7 days.

\section{Identification of fungi}

Each diseased onion sample (with petridish) was observed under a steriomicroscope at 10X and 25X magnifications in order to record the fungi. Most of the associated microorganisms were detected by observing their growth characters on the incubated diseased onion on blotter and PDA following the keys outlined by Barnett (1965). For confirmation temporary slides were prepared from the pure cultured fungal colony and observed under a compound microscope, then identified with the help of keys suggested by Booth (1971) and Ellis (1971). Identified pure cultures were indicated as isolates.

\section{Pathogenicity test}

Pathogenicity tests of the isolates were done to be certain about the disease causing ability of the organism(s) by inoculating the isolates in healthy onions by with or without pricking and then incubating at $22-23^{\circ} \mathrm{C}$ and observed for 7-90 days. Incase of disease development symptoms were observed and pathogens were re-isolated and identified satisfying Koch's postulates. The \% disease developments were recorded in the test onions by eye estimation.

\section{Results and Discussion}

\section{Detection and identification of fungi associated with stored onion bulbs}

Four local varieties namely Taherpuri, Faridpuri, Kalashnagari, Zitka and one Indian variety Pusa Red were under scrutiny. Five different fungi were repeatedly isolated and identified by PDA plate incubation method. These fungi were Aspergillus niger, A. flavus, Penicillium spp., Fusarium oxysporum, and F. moniliforme.

\section{Pathogenicity test}

On artificial inoculation (with injury and without injury) to healthy onions all of the five fungiAspergillus niger, A. flavus, Penicillium spp., Fusarium oxysporum and F. moniliforme produced characteristics symptoms in the inoculated onion bulbs. Control bulbs did not show any disease symptoms.

Aspergillus niger was found infectious in all varieties of onion bulbs (Taherpuri, Faridpuri, Kalashnagari, Zitka and Pusa Red) upon inoculation with injury and without injury. Test onion bulbs of the cultivar Pusa Red had the highest $22.25 \%, 36.0 \%$ and $44.17 \%$ disease development at 30,60 and 90 days after inoculation with injury. In the inoculation without injury $8.08 \%, 10.58 \%$ and $13.83 \%$ disease development was observed at 30,60 and 90 days respectively, whereas the cultivar Zitka showed lowest disease development and it was 14.58 (with injury) and 4.00 (without injury) at 90 days after inoculation. The other cultivars under scrutiny developed mediocre disease development (Table 1). 
Ara et al.

Table 1. Percentage disease development by Aspergillus niger after different days of post inoculation incubation

\begin{tabular}{|c|c|c|c|c|c|c|}
\hline \multirow{3}{*}{ Variety } & \multicolumn{6}{|c|}{ Aspergillus niger } \\
\hline & \multicolumn{2}{|c|}{30 days } & \multicolumn{2}{|c|}{60 days } & \multicolumn{2}{|c|}{90 days } \\
\hline & With injury & Without injury & With injury & Without injury & With injury & Without injury \\
\hline Taherpuri & $18.17^{b}$ & $6.00^{b}$ & $26.08^{b}$ & $10.08^{a}$ & $33.50^{b}$ & $12.83^{b}$ \\
\hline Faridpuri & $13.00^{C}$ & $3.41^{c}$ & $18.50^{C}$ & $5.58^{b}$ & $25.00^{\mathrm{bc}}$ & $8.50^{c}$ \\
\hline Kalashnagari & $11.92^{\mathrm{C}}$ & $3.41^{c}$ & $17.25^{d}$ & $5.33^{b}$ & $22.67^{\mathrm{bc}}$ & $7.58^{d}$ \\
\hline Zitka & $7.58^{d}$ & $1.08^{d}$ & $10.92^{\mathrm{e}}$ & $2.08^{\mathrm{C}}$ & $14.58^{c}$ & $4.00^{\mathrm{e}}$ \\
\hline Pusa Red & $22.25^{a}$ & $8.08^{a}$ & $36.00^{a}$ & $10.58^{\mathrm{a}}$ & $44.17^{a}$ & $13.83^{a}$ \\
\hline LSD & 0.60 & 0.25 & 0.38 & 0.25 & 4.49 & 0.30 \\
\hline CV (\%) & 15.63 & 12.36 & 10.23 & 11.58 & 29.36 & 10.23 \\
\hline Level of sig. & ** & ** & ** & ** & ** & ** \\
\hline
\end{tabular}

In a column figures with same letter or without letter do not differ significantly whereas figures with dissimilar letter differ significantly (as per DMRT)

** $=$ Significant at $1 \%$ level of probability

Though appeared less virulent compared to Aspergillus niger, disease development was found in all the varieties of test onion bulbs when inoculated with Aspergillus flavus. After 30 days of inoculation with injury, disease development was highest in Pusa Red variety and it was $12.33 \%$; and lowest in Zitka variety (6.42\%). Aspergillus flavus did hardly show auto driven penetration into onion tissue when inoculated without injury. The cultivar Pusa Red showed highest disease development of only $5.00 \%$. Lowest disease was found in Zitka variety and it was only $0.41 \%$ (Table 2 ).

Table 2. Percentage disease development by Aspergillus flavus after different days of post inoculation incubation

\begin{tabular}{|c|c|c|c|c|c|c|}
\hline \multirow{3}{*}{ Variety } & \multicolumn{6}{|c|}{ Aspergillus flavus } \\
\hline & \multicolumn{2}{|c|}{30 days } & \multicolumn{2}{|c|}{60 days } & \multicolumn{2}{|c|}{90 days } \\
\hline & With injury & Without injury & With injury & Without injury & With injury & Without injury \\
\hline Taherpuri & $11.58^{\mathrm{b}}$ & $1.58^{b}$ & $15.08^{b}$ & $3.00^{b}$ & $21.58^{b}$ & $5.00^{c}$ \\
\hline Faridpuri & $10.66^{\mathrm{C}}$ & $0.58^{\mathrm{C}}$ & $15.08^{b}$ & $1.83^{\mathrm{C}}$ & $19.00^{C}$ & $3.33^{d}$ \\
\hline Kalashnagari & $9.00^{d}$ & $1.83^{b}$ & $13.50^{C}$ & $3.41^{b}$ & $16.58^{\mathrm{d}}$ & $5.66^{b}$ \\
\hline Zitka & $6.42^{\mathrm{e}}$ & $0.41^{c}$ & $9.91^{d}$ & $1.08^{d}$ & $13.16^{\mathrm{e}}$ & $2.58^{\mathrm{e}}$ \\
\hline Pusa Red & $12.33^{a}$ & $5.00^{a}$ & $18.58^{a}$ & $7.00^{\mathrm{a}}$ & $26.75^{\mathrm{a}}$ & $8.58 a$ \\
\hline LSD & 0.34 & 0.22 & 0.23 & 0.18 & 0.33 & 0.347 \\
\hline CV (\%) & 12.45 & 17.54 & 15.44 & 16.00 & 9.52 & 16.54 \\
\hline Level of sig. & ** & ** & ** & ** & ** & ** \\
\hline
\end{tabular}

In a column figures with same letter or without letter do not differ significantly whereas figure with dissimilar letter differ significantly (as per DMRT)

** = Significant at $1 \%$ level of probability

Even after 90 days of inoculation with injury, the \% disease development in Pusa Red was highest $(26.75 \%)$ and Zitka had the lowest (13.16\%). And in case of inoculation without injury, $\%$ disease development in cultivar Pusa Red raised to only 8.58. In only two other varieties, after 90 days of inoculation the \% disease development was more than $5 \%$ (cv Taherpuri and cv. Kalashnagari). On the basis of susceptibility to Aspergillus flavus with injury (high to low) the cultivars may be arranged in the following order i) Pusa Red ii) Taherpuri iii) Faridpuri iv) Kalashnagari and v) Zitka (Table 2). Aspergillus flavus was found to be less aggressive as an intruder into healthy onion tissue. 
In terms of virulence and percent disease development after inoculation and incubation at favourable environment, the pathogens Penicillium spp.were found to have relatively having higher pathogenicity than that of Aspergillus flavus when considered \% disease development without injury. Pusa Red cv. was most vulnerable to Penicillium spp. whereas cv. Taherpuri was the most vulnerable in uninjured condition closely followed by cv. Faridpuri and cv. Kalashnagari. The cv. Zitka was found to be least vulnerable to Penicillium infections (Table 3).

Table 3. Percentage disease development by Penicillium spp. after different days of post inoculation incubation

\begin{tabular}{|c|c|c|c|c|c|c|}
\hline \multirow{3}{*}{ Variety } & \multicolumn{6}{|c|}{ Penicillium spp. } \\
\hline & \multicolumn{2}{|c|}{30 days } & \multicolumn{2}{|c|}{60 days } & \multicolumn{2}{|c|}{90 days } \\
\hline & With injury & Without injury & With injury & Without injury & With injury & Without injury \\
\hline Taherpuri & $10.50^{\mathrm{b}}$ & $4.33^{\mathrm{a}}$ & $19.16^{\mathrm{b}}$ & $7.25^{a}$ & $28.66^{\mathrm{b}}$ & $9.33^{\mathrm{a}}$ \\
\hline Faridpuri & $10.33^{b}$ & $1.17^{\mathrm{c}}$ & $15.83^{c}$ & $4.00^{b}$ & $22.00^{C}$ & $6.25^{b}$ \\
\hline Kalashnagari & $9.58^{\mathrm{C}}$ & $2.00^{b}$ & $14.00^{\mathrm{d}}$ & $4.00^{\mathrm{b}}$ & $17.83^{\mathrm{d}}$ & $6.41^{b}$ \\
\hline Zitka & $5.83^{d}$ & $0.33^{\mathrm{d}}$ & $9.50^{\mathrm{e}}$ & $0.75^{\mathrm{d}}$ & $12.58^{\mathrm{e}}$ & $1.83^{\mathrm{C}}$ \\
\hline Pusa Red & $15.33^{\mathrm{a}}$ & $2.17^{b}$ & $22.00^{\mathrm{a}}$ & $3.41^{\mathrm{c}}$ & $31.91^{\mathrm{a}}$ & $6.41^{b}$ \\
\hline LSD & 0.34 & 0.26 & 0.22 & 0.21 & 0.34 & 0.22 \\
\hline CV (\%) & 12.55 & 19.65 & 9.58 & 12.47 & 8.52 & 10.47 \\
\hline Level of sig. & ** & ** & ** & ** & ** & ** \\
\hline
\end{tabular}

In a column figures with same letter or without letter do not differ significantly whereas figures with dissimilar letter differ significantly (as per DMRT)

** $=$ Significant at $1 \%$ level of probability

Fusarium oxysporum and Fusarium moniliforme which caused Fusarium dry rot and basal rot of onion were found to be very weak pathogens of onion compared to the Aspergillus spp. and Penicillium spp.. Only injured onion bulbs were found to develop significant \% disease development when inoculated with Fusarium oxysporum whereas F. moniliforme was found to produce significant disease development with or without injury although in a very low scale. The cultivars Faridpuri, Kalashnagari and Pusa Red were more vulnerable to the infecting Fusaria whereas the cv. Zitka was found least vulnerable (Table 4 and 5).

Table 4. Percentage disease development by Fusarium oxysporum after different days of post inoculation incubation

\begin{tabular}{|c|c|c|c|c|c|c|}
\hline \multirow{3}{*}{ Variety } & \multicolumn{6}{|c|}{ Fusarium oxysporum } \\
\hline & \multicolumn{2}{|c|}{30 days } & \multicolumn{2}{|c|}{60 days } & \multicolumn{2}{|c|}{90 days } \\
\hline & With injury & Without injury & With injury & Without injury & With injury & Without injury \\
\hline Taherpuri & $1.08^{\mathrm{a}}$ & 0.17 & $1.92^{b}$ & 0.58 & $2.42^{b}$ & 1.00 \\
\hline Faridpuri & $1.25^{\mathrm{a}}$ & 0.08 & $2.75^{\mathrm{a}}$ & 0.50 & $3.66^{\mathrm{a}}$ & 0.83 \\
\hline Kalashnagari & $0.50^{b}$ & 0.17 & $1.75^{\mathrm{b}}$ & 0.58 & $3.25^{a}$ & 1.08 \\
\hline Zitka & $0.41^{\mathrm{b}}$ & 0.00 & $0.83^{c}$ & 0.33 & $1.50^{c}$ & 0.50 \\
\hline Pusa Red & $1.17^{\mathrm{a}}$ & 0.33 & $2.00^{b}$ & 0.50 & $3.25^{\mathrm{a}}$ & 0.83 \\
\hline LSD & 0.21 & 0.14 & 0.18 & 0.13 & 0.23 & 0.19 \\
\hline CV (\%) & 20.36 & 29.33 & 16.38 & 22.65 & 12.65 & 22.36 \\
\hline Level of sig. & ** & NS & ** & NS & ** & NS \\
\hline
\end{tabular}

In a column figures with same letter or without letter do not differ significantly whereas figures with dissimilar letter differ significantly (as per DMRT)

** $=$ Significant at $1 \%$ level of probability,

NS $=$ Not significant 
Ara et al.

Table 5. Percentage disease development by Fusarium moniliforme after different days of post inoculation incubation

\begin{tabular}{|c|c|c|c|c|c|c|}
\hline \multirow{3}{*}{ Variety } & \multicolumn{6}{|c|}{ Fusarium moniliforme } \\
\hline & \multicolumn{2}{|c|}{30 days } & \multicolumn{2}{|c|}{60 days } & \multicolumn{2}{|c|}{90 days } \\
\hline & With injury & Without injury & With injury & Without injury & With injury & Without injury \\
\hline Taherpuri & $1.33^{\mathrm{a}}$ & 0.17 & $2.08^{a}$ & $0.58^{b}$ & $2.50^{c}$ & $0.92^{\mathrm{bc}}$ \\
\hline Faridpuri & $1.17^{\mathrm{ab}}$ & 0.17 & $1.66^{b}$ & $0.50^{b}$ & $3.75^{\mathrm{a}}$ & $0.83^{c}$ \\
\hline Kalashnagari & $0.83^{b}$ & 0.41 & $2.00^{\mathrm{ab}}$ & $1.08^{\mathrm{a}}$ & $3.08^{b}$ & $1.41^{\mathrm{a}}$ \\
\hline Zitka & $0.17^{c}$ & 0.00 & $0.75^{c}$ & $0.17^{\mathrm{c}}$ & $1.75^{d}$ & $0.66^{c}$ \\
\hline Pusa Red & $1.33^{\mathrm{a}}$ & 0.17 & $2.50^{\mathrm{a}}$ & $0.66^{b}$ & $2.83^{\mathrm{bc}}$ & $1.17^{\mathrm{ab}}$ \\
\hline LSD & 0.17 & 0.15 & 0.19 & 0.20 & 0.27 & 0.20 \\
\hline $\mathrm{CV}(\%)$ & 20.58 & 4.25 & 18.00 & 28.65 & 18.56 & 20.33 \\
\hline Level of sig. & ** & NS & $\star \star$ & ** & ** & ** \\
\hline
\end{tabular}

In a column figures with same letter or without letter do not differ significantly whereas figures with dissimilar letter differ significantly (as per DMRT)

** $=$ Significant at $1 \%$ level of probability

NS = Not significant

Fungi associated with storage diseases of marketed onions belonging to cultivars Taherpuri, Faridpuri, Kalashnagari, Zitka and Pusa Red, these were isolated, identified and confirmed through infectivity test. Five species of 3 genera of fungi were isolated and identified from collected diseased samples. These were Aspergillus niger, Aspergillus flavus, Penicillium spp., Fusarium oxysporum and Fusarium moniliforme. Among these fungi Aspergillus niger, Aspergillus flavus and Penicillium spp. were more predominant in stored onion bulbs, whereas Fusarium oxysporum and Fusarium moniliforme were occasionally found in stored onion bulbs. Aspergillus niger is the cause of black mould of onion, which is primarily a post harvest disease (Tyson and Fullerton, 2004). Fungi (Aspergillus niger and Penicillium spp.) were isolated from bulbs that showed typical disease symptoms (Velez et al., 2004). Percent disease development was examined for five onion cultivars through artificial inoculation to healthy onion bulbs through with and without injury. The test bulbs were observed for 90 days. Inoculation was done separately with 5 fungi viz. Aspergillus niger, A. flavus, Penicillium spp., Fusarium oxysporum and F. moniliforme. Observation of disease development was made at 30 days after inoculation and then at 30 days interval up to 90 days. Highest disease development was found after 90 days of inoculation than other two shorter durations in all the test varieties of onion. The disease development was significantly different among the varieties. The cultivar Pusa Red was found more susceptible to disease than the bulbs of other cultivars and the cultivar Zitka was found rather resistant. The varietal susceptibility of 11 onion cultivars to Fusarium oxysporum f.sp. cepae was investigated in the field, at harvesting and after storage (Visser, 1999). This finding emphasize the importance of injury to the bulb, incurred before or during storage and this was the key factor in storage disease development causing storage loss. The results of this present study indicate that the fungal diseases (black mould rot, blue mould rot and Fusarium bulb rot) are serious problem of onion bulb in Bangladesh and loss due to these diseases may be minimized by taking measures in the field, during transit and in storage so that the bulbs are not injured. 

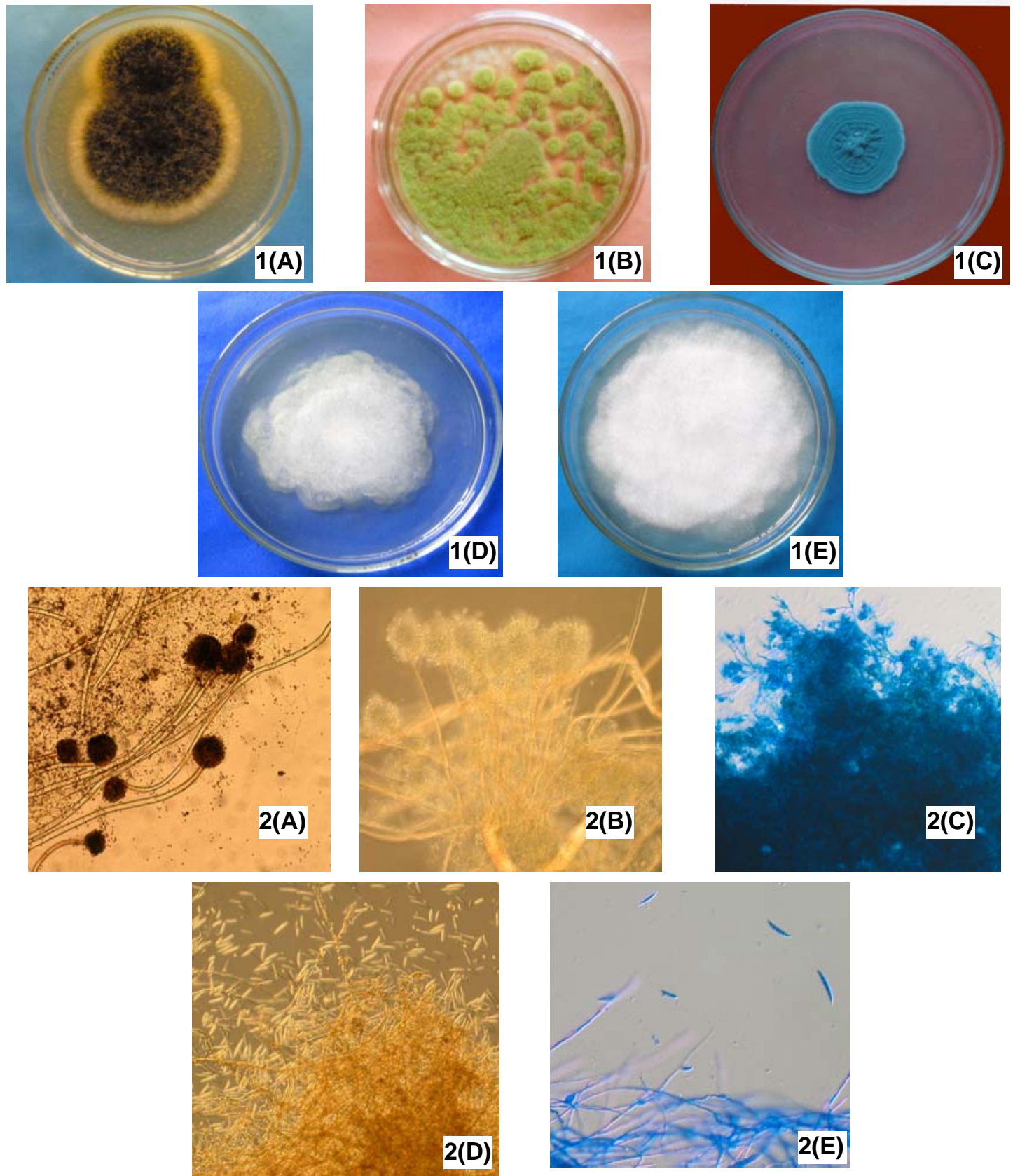

Plate: 1. (A) Growth of Aspergillus niger on PDA medium, 7 days old; 1 (B) Growth of $A$. flavus on PDA medium, 9 days old; 1 (C) Growth of Penicillium spp. on PDA medium, 9 days old; 1 (D) Growth of Fusarium oxysporum on PDA medium, 7 days old; 1 (E) Growth of $F$. moniliforme on PDA medium, 10 days old.

2. (A) Conidia, Conidiophores and conidial heads of Aspergillus niger (X 200); 2 (B) Conidia, Conidiophores and conidial heads of $A$. flavus (X 200); 2 (C) Conidia, brush like Conidiophores and phialide of Penicillium Spp. (X 100); 2 (D) Mycelia, macro and micro Conidia of Fusarium oxysporum (X 200); 2 (E) Mycelia, macro and micro Conidia of $F$. moniliforme (X 200). 
Ara et al.

\section{References}

Aiyer, A.K.N. 1980. Field crops of India with special reference to Karnataka, ( $7^{\text {th }}$ ed.). Bangalore. BAPPCO.

Barnett, H.L. 1965. Illustrated genera of imperfect fungi. Bugress Publishing Co. 225p.

Booth, C. 1971. The Fusarium Commonwealth Mycol. Inst. Kew, Survey, England. 236p.

Ellis, M.B. 1971. Dematiaceous Hypomycetes. CMI, Kew survey, English. 507p.

Jones, H.A. and Mann, L.K. 1963. Onions and their allies. Interscience publishers. Inc.New York.

Overy, D.P., Frisvad, J.C., Steinmeier, U. and Thrane, U. 2005. Clarification of the agents causing blue mold storage rot upon various flower and vegetable bulbs: implications for mycotoxin contamination. Postharvest Biology and Technology. 35(2): 217-221.

Tyson, J. L. and Fullerton, R.A. 2004. Effect of soil-borne inoculum on incidence of onion black mould (Aspergillus niger). New Zealand Plant Protection, Volume-57, Proceedings of a conference, Hamilton, New Zealand, 10-12 August .138-141.

Velez, L., Rivera, L.I., Rodriguez, R.P. and Cabrera, I. 2004. Fungi associated with onion (Allium cepa L.) fields in southern Puerto Rico.Journal of Agriculture of the University of Puerto Rico. 88(1/2): 55-72.

Visser, C.L.M. 1999. Fusarium in onions and varietal differences in infection: evaluation of a biotest. PAV Bulletin Vollegrondsgroenteteelt. 4-7. 